\title{
Providing artificial nest platforms for Cabot's tragopan Tragopan caboti (Aves: Galliformes): a useful conservation tool?
}

\author{
Wen-hong Deng, Guang-mei Zheng, Zheng-wang Zhang, Peter J. Garson and Philip J. K. McGowan
}

\begin{abstract}
Cabot's tragopan Tragopan caboti, a pheasant that inhabits subtropical montane forests in south-east China, is categorized as Vulnerable on the IUCN Red List. Nesting in trees, it routinely makes use of natural platforms and the old nests of other species, both of which may sometimes be in short supply. This study was designed to test how much use would be made of artificial nest platforms, and to identify factors influencing their occupation. Basketry platforms made of bamboo were erected in parts of Wuyanling National Nature Reserve, Zhejiang Province, China. The tragopans used 16 platforms $(8 \%)$ in 2002 and $12(5 \%)$ in the following year. A census of the population in spring suggested that a high proportion of the females $(41 \%$ in $2002,36 \%$ in 2003) in the study area made use of the platforms. There were significant preferences for platforms in mixed
\end{abstract}

conifer/broadleaf forest, as opposed to pure stands, as well as for sites on the upper part of hill slopes. Principal component scores were used to represent variation in 11 variables measured at each platform site. Binary logistic regressions employing these scores as predictors for each year separately did not reveal a consistent model for distinguishing used from unused platforms, although short distances to the forest edge were associated with use in both years. These nest platforms are cheap and easy to erect, and may have the potential to halt or reverse a perceived downward population trend for this species across the whole of its fragmented range. Further trials are therefore advocated.

Keywords Artificial nest platform, China, Galliformes, pheasant, Tragopan caboti, Wuyanling National Nature Reserve, Zhejiang.

\section{Introduction}

Cabot's tragopan Tragopan caboti is a pheasant endemic to south-east China's dense montane (700-1,300 m altitude) forests (Zheng et al., 1985; Johnsgard, 1986). Over the last 50 years much of its natural habitat has been cleared for conversion to commercial conifer plantations or agricultural land. It still occurs over much of its historical range in the provinces of Zhejiang, Jiangxi, Guangxi, Guangdong and Hunan, but its distribution is now highly fragmented. Within the last 15 years it has apparently disappeared from several counties in Fujian Province in the extreme east of its distribution (Zhang \& Zheng, 1990a). It is currently categorized as Vulnerable (BirdLife International, 2004; IUCN, 2004), on the basis of criteria (IUCN, 2001) C2a(I); i.e. continuing decline in

Deng Wen-hong (Corresponding author), Zheng Guang-mei and Zhang Zheng-wang Ministry of Education Key Laboratory for Biodiversity Science and Ecological Engineering, College of Life Science, Beijing Normal University, Beijing 100875, China. E-mail dengwh@bnu.edu.cn

Peter J. Garson School of Biology, King George VI Building, University of Newcastle, Newcastle upon Tyne, NE1 7RU, UK.

Philip J.K. McGowan World Pheasant Association, 7-9 Shaftesbury Street, Fordingbridge, SP6 1JF, UK

Received 12 February 2003. Revision requested 1 July 2003. Accepted 3 November 2004. a fragmented population of $<10,000$ mature individuals that has no subpopulation of more than 1,000 (Fuller \& Garson, 2000). It is also listed in Appendix I of CITES (2003) and as a National First Class Protected Species in China (Zheng \& Wang, 1998).

Studies of its breeding ecology (Zheng et al., 1985; Zheng \& Zhang, 1990) have shown that, like its congeners but unlike all other pheasants, this species typically nests in trees (Johnsgard, 1999). For this purpose it uses not only natural platforms such as forks between branches or other places where dead twigs and leaves accumulate, but also the abandoned nests of red squirrels Sciurus vulgaris, corvids such as red-billed choughs Pyrrhocorax pyrrhocorax, and other birds. It seems to have little ability to build a nest without these pre-existing structures, giving rise to the possibility that nest site availability may limit breeding density, especially in areas used for timber production where large spreading tree canopies are scarce.

In this paper we present the results of a study of the use of artificial nest platforms by Cabot's tragopan in natural mixed forest and conifer plantations. Our aims were to determine the extent to which this species will use these platforms and to characterize the type of artificial nest sites they favour. From these findings we draw tentative conclusions about the potential 

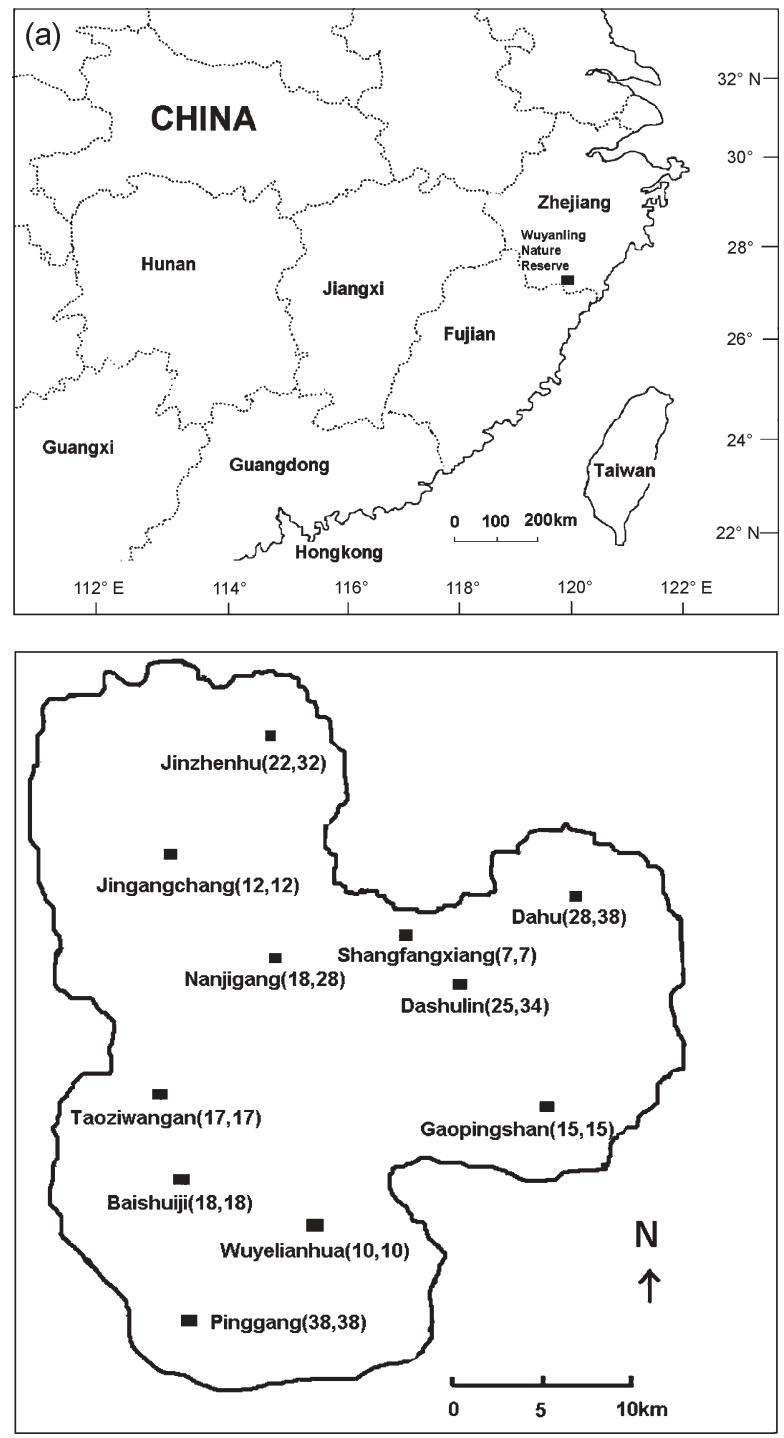

Fig. 1 (a) The location of Wuyanling National Nature Reserve in Zhejiang Province, China, and (b) locations of the 11 study sites in the Reserve, with numbers of artificial nest platforms erected at each site (in 2002, 2003).

usefulness of erecting nest platforms as a conservation tool for this species.

\section{Methods}

Fieldwork was conducted during February-May in 2002 and 2003 at Wuyanling National Nature Reserve, Zhejiang Province, China (Fig. 1a), a managed forest of c. $200 \mathrm{~km}^{2}$. The Reserve is situated in the mid subtropical zone at an elevation of 500-1,400 m, with a mean annual temperature of $16.8^{\circ} \mathrm{C}$ and rainfall of c. $2,000 \mathrm{~mm}$ per year. The work was carried out within the $64 \mathrm{~km}^{2}$ core area reserved for wildlife conservation (especially Cabot's tragopan), and a $60 \mathrm{~km}^{2}$ area in the surrounding buffer zone. The dominant native tree species are Eyer evergreen chinkapin Castanopsis eyeri, crenate gugertree Schima crenata, Chinese fir Cunninghamia lanceolata, many-vein oak Cylobabanopsis multinervis, Chinese cedar Cryptomeria fortunei, bitter evergreen chinkapin Castanopsis sclerophylla and myrsina-leaf oak Cylobabanopsis myrsinaefolia. Both the core and buffer zones contain areas of conifer planted in the 1960s and are composed of Huangshan pine Pinus huangshanensis, Chinese fir and Chinese cedar. Hard green bamboo Phyllostachys veitchiana and Guangxi bamboo P. kwangsiensis are widely distributed at lower elevations.

In both years a population estimate for Cabot's tragopan was made using count data obtained from line transects at 11 sites (Fig. 1b) during the pre-breeding and breeding seasons in March-May. Transects were walked with well-trained dogs (Jenkins et al., 1963) at least three times each, both after dawn and before dusk, when the birds are most active. Birds were classified into age (adult, yearling for males only) and sex classes by size, plumage and voice (Zhang \& Zheng, 1990a). During the transect walks, perpendicular distances from the transect line were recorded for all birds detected. These data were pooled within sites and analysed using standard Distance Sampling analysis (Buckland et al., 1993) to produce estimates of the numbers of tragopans of each sex for each plot.

Males detected by their territorial call were mapped (Bibby et al., 1992) on three other occasions at each transect site to provide an independent check on one part of the population's size. We did not carry out transect walks or call counts in bad weather conditions.

The nest platforms were all of the same design, constructed from bamboo strips to produce a basketry bowl of height $15 \mathrm{~cm}$ and diameter $30 \mathrm{~cm}$ (Plate 1). In February 2002 they were fixed to trees with wire, at least

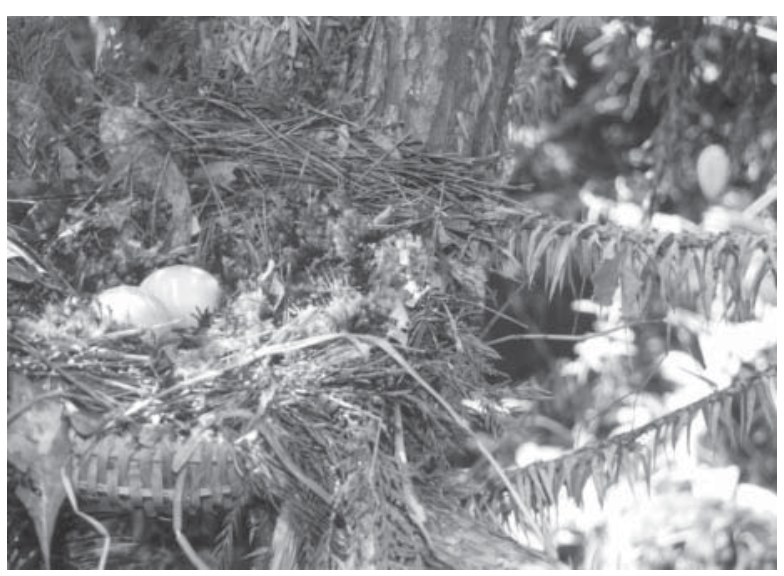

Plate 1 Two Cabot's tragopan eggs in a nest on a bamboo basketry platform. 
$100 \mathrm{~m}$ apart, throughout the 11 sites used for the line transect counts. Two hundred platforms were erected in all, with varying numbers at each site according to their accessibility and the habitats present (Fig. 1b). Overall they were allocated as follows: 65 in conifer blocks, 65 in broadleaf areas, and 70 in mixed conifer-broadleaf areas with half in each tree type. The range of heights from the ground was $1.4-10.5 \mathrm{~m}$, within an altitude range of $650-1,580 \mathrm{~m}$, reflecting the distribution of natural nests found in this and earlier studies at Wuyanling $(\mathrm{n}=21$; mean \pm 1 SD $1,082 \pm 169 \mathrm{~m}$ for altitude; $4.3 \pm 1.9 \mathrm{~m}$ for nest height; Ding \& Zheng, 1996, 1997). In February 2003, 107 of the original platforms were repaired and repositioned, and 39 more were erected, so that there were then 63 in conifer, 97 in mixed and 79 in broadleaf forests, but still with half the platforms on each tree type. Given these rearrangements, the results from the two seasons are regarded as independent. In March-April each year all platforms were checked weekly for signs of nesting activity (i.e. nesting material, feathers, sitting female, eggs or eggshells).

At each tree fitted with a platform, aspect was measured with a compass, slope angle (\%) with a clinometer, relative canopy closure (\%) with a spherical densitometer, elevation with an altimeter, tree diameter at breast height $(\mathrm{DBH})$ with calipers, and tree height with a clinometer Slope position (lower, middle or upper thirds) was noted. We measured the distance from platform trees to the nearest running water and forest edge (with scrub, grass or recently felled areas).

Natural nests were located by walking through all the sites with two dogs trained to bark and therefore flush any tragopans that they detected (Zheng, 1987; Zhang \& Zheng, 1990b). We only found nine natural nests in this way, but data on another 12 were available to us from previous studies (Ding \& Zheng, 1996, 1997).

\section{Results}

In 2002 the line transect data gave an estimated total of 90 adult tragopans in the 11 study sites (51 males and 39 females). Mapping of male calling positions gave totals of 51,39 and 41 , i.e. a mean of 44 resident birds in the 11 sites. In 2003 the line transect data gave an estimated total of 78 adults (43 males, 35 females), and the census of calling males gave a total of 49 (Table 1). In 2002, 16 nesting attempts were made on the artificial platforms (Table 1), representing $8 \%$ of the platforms available and $41 \%$ of the adult females estimated to have been present. Twelve (5\%) platforms were used by an estimated $36 \%$ of the females present in 2003.

Given the relatively large number of habitat descriptors recorded at each platform location, principal components analysis was used to reduce the variables to a smaller number of independent, composite variables.
Table 1 Transect length and number, and estimated number of female and male Cabot's tragopans and number of nest platforms used at 11 sites (see Fig. 1b for locations) in Wuyanling National Nature Reserve in 2002 and 2003.

\begin{tabular}{lllll}
\hline & $\begin{array}{l}\text { Transect } \\
\text { length }(\mathrm{km}) \\
\text { (and number) }\end{array}$ & $\begin{array}{l}\text { Female, } \\
\text { male in }\end{array}$ & $\begin{array}{l}\text { Female, } \\
\text { male in } \\
\text { 2002 }\end{array}$ & $\begin{array}{l}\text { Used } \\
\text { platforms } \\
2002,2003\end{array}$ \\
\hline Dashulin & $2.8(2)$ & 4,6 & 3,5 & 3,1 \\
Dahu & $5.2(2)$ & 8,5 & 6,5 & 2,3 \\
Jinzhenhu & $5.6(2)$ & 3,5 & 4,4 & 3,2 \\
Taoziwangan & $2.1(2)$ & 0,4 & 1,4 & 2,1 \\
Wuyelianhua & $2.0(2)$ & 2,7 & 3,5 & 0,0 \\
Nanjigang & $4.3(3)$ & 6,5 & 4,3 & 3,2 \\
Shangfangxiang & $2.0(2)$ & 1,0 & 1,0 & 0,1 \\
Gaopingshan & $2.5(1)$ & 2,4 & 3,3 & 0,0 \\
Pinggang & $7.5(3)$ & 6,5 & 5,2 & 1,1 \\
Baishuiji & $2.0(2)$ & 2,7 & 2,7 & 1,0 \\
Jingangchang & $2.0(2)$ & 5,3 & 3,5 & 1,1 \\
Totals & $38.0(23)$ & 39,51 & 35,43 & 16,12 \\
\hline
\end{tabular}

In both years the first axis (PC1) represented c. $25 \%$ of the variation, and the next three (PC2-4) included an additional $10-15 \%$ each. The influence of the measured variables on the PC scores varied between years, although forest type, tree species and slope position all influenced PC1 strongly in the same direction in both years.

Used platforms were sited mainly within blocks of mixed-conifer/broadleaf forest $(63 \%$ in $2002 ; 83 \%$ in 2003; pooled $\chi^{2}=13.26, \mathrm{df}=2, \mathrm{P}<0.005$; Fig. $2 \mathrm{a}$ ), rather than in areas of pure conifer or broadleaf. They were located in eight tree species, mostly in conifers, especially Chinese cedar $(69 \%$ in $2002 ; 67 \%$ in 2003 ; pooled $\left.\chi^{2}=3.72, \mathrm{P}>0.05\right)$. The majority of natural nests $(48 \%$, $n=21$ ) found at Wuyanling in this and previous studies were in broadleaf forest, although a strict comparison with the used platforms is not valid because the natural nests were found through a non-systematic search with the help of dogs. Used platforms were also found predominantly on the upper portions of hill slopes (75\% in both years; pooled $\chi^{2}=27.3, \mathrm{df}=2, \mathrm{P}<0.001$; Fig. 2b).

Binary logistic regression was used to distinguish used from unused platforms, using PC1-4 as potential predictors. In 2002 used platforms had high scores for PC2 $(\mathrm{Z}=4.28, \mathrm{P}<0.001)$ and PC3 $(\mathrm{Z}=3.10, \mathrm{P}=0.002)$ by comparison with unused platforms (Fig. 3a). PC2 scores are positively correlated with both tree height and nest height. High PC3 values are associated with upper altitudes, high canopy cover and short distances to the forest edge. In 2003 the circumstances and surroundings of used platforms again differed from unused ones (Fig. 3b), but only PC4 had a strong effect $(Z=3.64$, $\mathrm{P}<0.001)$. Scores on this axis are high when angle of slope is low and distance to the forest edge is short. 

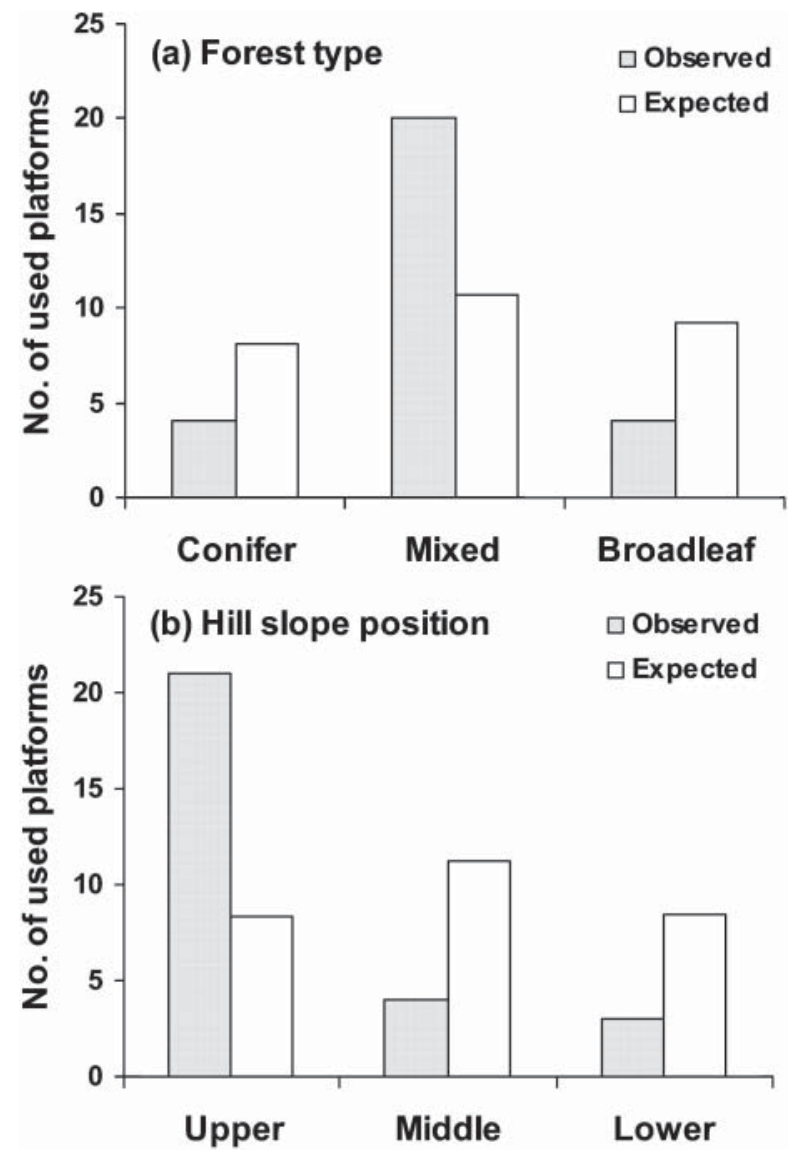

Fig. 2 Distribution of used platforms across (a) three forest types and (b) three hill slope positions. Data for 2002 and 2003 were homogeneous and therefore pooled. Expected numbers are generated from the proportional distribution of all platforms erected across categories in each year.

\section{Discussion}

The total number of female Cabot's tragopans that attempted to breed in the 11 sites where nest platforms were supplied remains unknown, because a systematic search for natural nests was impractical. Some of the females estimated to have been present from the line transect data will have been yearlings, which in captivity are not known to normally make breeding attempts (Wen \& Zheng, 1997; Zhang \& Zheng, 2002; J. Corder \& T. Lovel, pers. comm.). It is also unlikely that all the males mapped using their calls actually acquired both territories and mates. Both these biases imply that our estimates for the percentage of all breeding females that used the artificial platforms as nest sites in each year are probably less than the real number.

The implied high level of platform use may be taken as circumstantial evidence for a paucity of natural nest sites, which in turn may be limiting the number of breeding attempts made at Wuyanling. Equally, this result may be

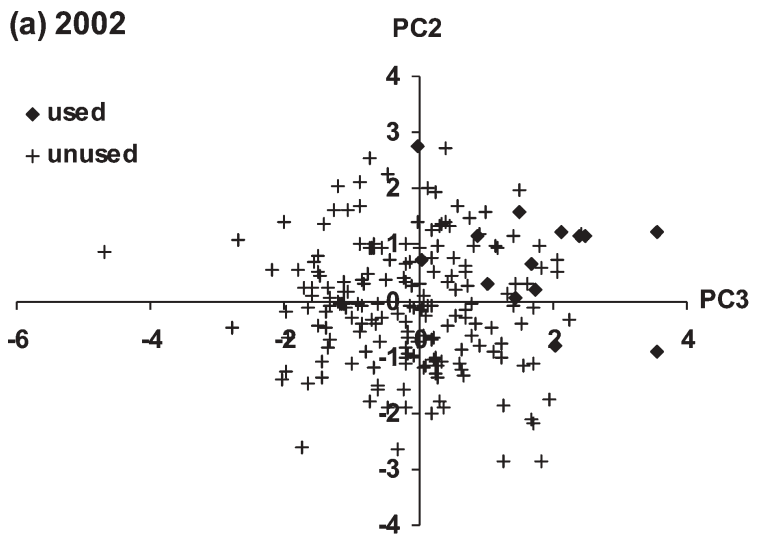

(b) $2003 \quad$ PC1

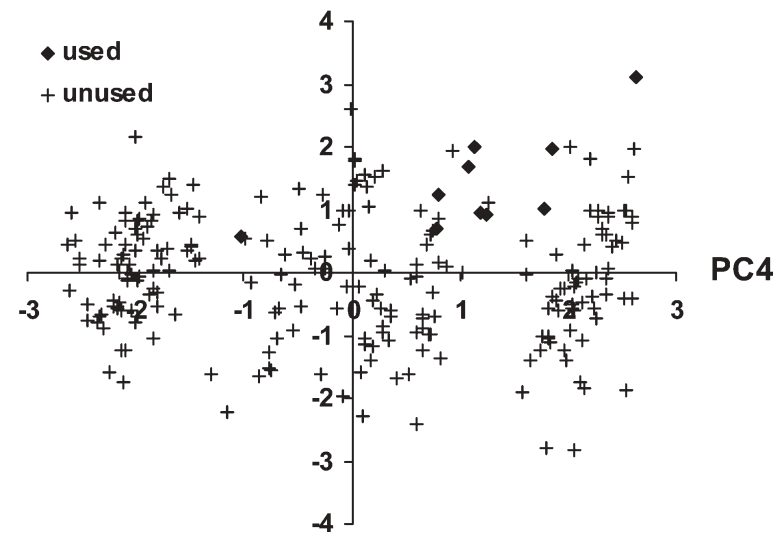

Fig. 3 Principal component (PC) plots for (a) 2002 and (b) 2003 showing that used platforms represent a subset of all the platforms erected. See text for interpretation of the four PC axes represented.

indicating that artificial platforms are selected in preference to natural sites by female tragopans. Provided one or other of these explanations is correct, the provision of nest platforms should increase the breeding output for the tragopan population as a whole. In the first case more nesting attempts should be possible, and in the second, if it is further assumed that nest site selection by females is adaptive, average productivity per nest should increase. However, this study does not provide direct evidence for either of these effects.

An earlier population survey at Wuyanling (Zhang \& Zheng, 1990b) found a much higher density (7.1 individuals $\mathrm{km}^{-2}$ ) of tragopans than the present study (0.9 individuals $\mathrm{km}^{-2}$ ). The earlier work was conducted entirely within the core area, whereas our study area included parts of the buffer zone, but it still seems likely that the tragopan population has decreased over the last decade. However, the indirect evidence that we have presented here suggests that a long-term programme for the provision of nesting platforms should result in a reversal of this trend at Wuyanling. 
Cabot's tragopan is a threatened species living in a number of isolated habitat patches (Zhang \& Zheng, 1990a), suggesting that the deployment of artificial nesting platforms more widely may prevent some of its small remnant populations from going extinct. This may prove to be particularly effective for the conservation of populations in areas where conifers were planted in the place of older natural broadleaf or mixed forests (this occurred up to 1998, when the Chinese government introduced a felling embargo for primary forests). The platforms are cheap to produce and easy to erect, making further trials feasible.

We have been able to show that the habitat surroundings of used platforms were a subset of all those available within each of the 2 years of this study. Although some of the characteristics of used platforms differed between years, they tended to be in natural mixed forest on the upper parts of hill slopes and close to the edge of the forest. This combination is characteristic of the tree line forest-scrub ecotone, where there is easy access to more open and productive habitats for newly-hatched chicks, which are known to subsist on invertebrates (Zhang, 1997).

Field work is still in progress at Wuyanling in an effort to determine the design, siting and habitat surroundings of the platforms that combine to maximize their use, along with attempts to establish the level of breeding success for females making use of platforms for nesting.

\section{Acknowledgements}

We thank Qiu Zhao-yun, Xu Yong-zhao, Pang Chengsong, Li Shi-min, Zheng Fang-dong, Zheng Chai, Mao Xiao-peng, Zheng Er-zhong and Tao Xia-hui of Wuyanling National Natural Reserve for their help. We especially thank Wu Jiu-zhong and Lan Jia-ren who accompanied us and put up artificial nests. We acknowledge financial support from the Natural Science Foundation of China (Grant No. 30330050) and the World Pheasant Association. We also thank the Cultural and Education Section of the British Embassy (the British Council) in Beijing for funding a workshop at Beijing Normal University in August 2002 that laid the foundations for the preparation of this paper.

\section{References}

Bibby, C.J., Burgess, N.D. \& Hill, D.A. (1992) Bird Census Techniques. Academic Press, London, UK.

BirdLife International (2004) Threatened Birds of the World 2004. $C D$-ROM. BirdLife International, Cambridge, UK [http://www.birdlife.org.uk/datazone/search/ species_search.html, accessed 3 November 2004].

Buckland, S.T., Anderson, D.R., Burnham, K.P. \& Laake, J.L. (1993) Distance Sampling: Estimating Abundance of Biological Populations. Chapman and Hall, London, UK.

CITES (2003) Checklist of CITES Species. UNEP-WCMC, Cambridge, UK [http:/ / www.cites.org/eng/resources/ species.html, accessed 3 November 2004].

Ding, C.Q. \& Zheng, G.M. (1996) A preliminary study on the reintroduction of Cabot's tragopan. Acta Zoologica Sinica, 42, 69-73. [in Chinese with English abstract]

Ding, C.Q. \& Zheng, G.M. (1997) The nest site selection of Cabot's tragopan (Tragopan caboti). Acta Zoologica Sinica, 43, 27-33. [in Chinese with English abstract]

Fuller, R.A. \& Garson, P.J. (2000) Pheasants: Status Survey and Conservation Action Plan 2000-2004. IUCN, Gland, Switzerland and World Pheasant Association, Reading, UK.

IUCN (2001) IUCN Red List Categories and Criteria Version 3.1. IUCN, Gland, Switzerland and Cambridge, UK [http://www.iucn.org/themes/ssc/redlists/ RLcats2001booklet.html, accessed 3 November 2004].

IUCN (2004) 2004 IUCN Red List of Threatened Species. IUCN, Gland, Switzerland [http:/ / www.redlist.org, accessed 17 November 2004].

Jenkins, D., Watson, A. \& Miller, G.R. (1963) Population studies on the red grouse Lagopus lagopus in northeast Scotland. Journal of Animal Ecology, 32, 347-376.

Johnsgard, P.A. (1999) The Pheasants of the World: Biology and Natural History. 2nd Edition. Smithsonian Institution Press, Washington, DC, USA.

Wen, Z.Q. \& Zheng, G.M. (1997) Study on breeding behavior of Cabot's tragopan. Journal of Beijing Normal University, 33, 63-269. [in Chinese with English abstract]

Zhang, J.P. \& Zheng, G.M. (1990a) The study of the population number and structure of Cabot's tragopan. Chinese Zoological Research, 11, 291-297. [in Chinese with English abstract]

Zhang, Y.Y. \& Zheng, G.M. (2002) A study on the artificial insemination of Cabot's tragopan (Tragopan caboti). Journal of Beijing Normal University, 38, 117-122.

Zhang, Z.W. (1987) The feeding ecology, nutrition and energy requirements of Cabot's tragopan. MSc thesis, Beijing Normal University, China. [in Chinese with English abstract]

Zhang, Z.W. \& Zheng, G.M. (1990b) Numbers and population structure of Cabot's tragopan (Tragopan caboti). In Pheasants in Asia 1989 (eds D.A. Hill, P.J. Garson \& D. Jenkins), pp. 48-53. World Pheasant Association, Reading, UK.

Zheng, G.M. (1987) The Cabot's tragopan. Chinese Journal Zoology, 22, 40-43. [in Chinese with English abstract]

Zheng, G.M. \& Wang, Q. (1998) China Red Data Book of Endangered Animals. Aves. Science Press, Beijing, China.

Zheng, G.M. \& Zhang, Z.W. (1990) Nest site selection and nest mortality of Cabot's tragopan in Wuyanling Natural Reserve. In Pheasants in Asia 1989 (eds D.A. Hill, P.J. Garson \& D. Jenkins), pp. 58-63. World Pheasant Association, Reading, UK.

Zheng, G.M., Zhao, X.R., Song, J., Liu, Z.X. \& Zhou, H.Q. (1985) On the breeding ecology of Cabot's tragopan. Acta Ecologica Sinica, 5, 379-385.

Zheng, G.M., Zhao, X.R., Song, J., Liu, Z.X. \& Zhou, H.Q. (1986) Feeding ecology of Cabot's tragopan. Acta Ecologica Sinica, 6, 283-288. [Chinese with English abstract] 
Biographical sketches

Deng Wen-hong's main research interests are in avian population ecology and conservation biology. Since 2001 he has been working on the effects of forest fragmentation on the distribution, density, and reproductive success of Cabot's tragopan.

Zheng Guang-mei is President of the China Ornithological Society. He and his research group have been studying Chinese bird species for nearly 40 years.

Zhang Zheng-wang and his research group study China's threatened bird species, including Cabot's tragopan, brown eared-pheasant and Reeves's pheasant.

Peter Garson is the Chair of the IUCN Species Survival Commission Pheasant Specialist Group. He has collaborated and advised on many projects concerned with species of Galliformes, particularly in China, India and Pakistan.

Philip McGowan has carried out fieldwork on Galliformes in India, China, Malaysia, Brunei and the Philippines since the early 1980s. 